\title{
The dynamic cusp aurora on 30 November 1997: response to southward turning of the IMF
}

\author{
P. E. Sandholt ${ }^{1}$, C. J. Farrugia ${ }^{2}$, B. Lybekk ${ }^{3}$ \\ ${ }^{1}$ Department of Physics, University of Oslo, Oslo, Norway \\ ${ }^{2}$ Institute for the Study of Earth, Oceans and Space, University of New Hampshire, Durham, NH, USA \\ ${ }^{3}$ Department of Physics, University of Oslo, Oslo, Norway
}

Received: 9 September 1998 / Revised: 7 January 1999 / Accepted: 26 January 1999

\begin{abstract}
We document the detailed dynamics of the dayside aurora in the $\sim 1200-1600$ MLT sector in response to a sharp southward turning of the interplanetary magnetic field (IMF) under negative IMF $B_{y}$ conditions. Features not documented in previous work are elucidated by using two meridan scanning photometers (separated by $2 \mathrm{~h}$ ) and an all-sky auroral imager in Ny Ålesund, Svalbard $\left(75.5^{\circ} \mathrm{MLAT}\right)$ in combination with magnetograms from stations on Svalbard, covering the latitude range $71^{\circ}-75^{\circ}$ MLAT. The initial auroral response may be divided into three phases consisting of: (1) intensification of both the red $(630.0 \mathrm{~nm})$ and green $(557.7 \mathrm{~nm})$ line emissions in the cusp aurora near 1200 MLT and $\sim 100 \mathrm{~km}$ equatorward shift of its equatorward boundary, at $\sim 75^{\circ}$ MLAT, (2) eastward and poleward expansions of the cusp aurora, reaching the 1430 MLT meridian after 5-6 min, and (3) east-west expansion of the higher-latitude aurora (at $\sim 77^{\circ}-78^{\circ}$ MLAT) in the postnoon sector. The associated magnetic disturbance is characterized by an initial positive deflection of the X-component at stations located 100-400 km south of the aurora, corresponding to enhanced Sunward return flow associated with the merging convection cell in the post-noon sector. The sequence of partly overlapping poleward moving auroral forms (PMAFs) during the first $15 \mathrm{~min}$, accompanied by corresponding pulsations in the convection current, was followed by a strong westward contraction of the cusp aurora when the ground magnetograms indicated a temporary return to the pre-onset level. These observations are discussed in relation to the Cowley-Lockwood model of ionospheric response to pulsed magnetopause reconnection.
\end{abstract}

Key words. Mangetospheric physics (magnetopause, cusp and boundary layers; solar wind-magnetosphere interactions; auroral phenomena)

\section{Introduction}

It is now well known that the process of magnetic reconnection between the interplanetary magnetic field (IMF) and the Earth's field at the dayside magnetopause at times occurs in a quasi-steady mode and at other times in a quasi-periodic mode (Russell et al., 1997). The physical source of the diversity of reconnection modes is not well known at present. Some of the more spectacular ionospheric manifestations of the different modes of solar wind-magnetosphere coupling are found in the dayside aurora. The strong regulation of the dayside aurora by the orientation of the IMF has been documented by Sandholt et al. (1998a, b, c). Three auroral configurations, corresponding to three regimes of the IMF clock angle in the Y-Z plane, $\theta$, have been identified. The first consists of a high-latitude $\left(\sim 78-79^{\circ} \mathrm{MLAT}\right)$ aurora observed during northward IMF orientation, i.e. in clock angle regime 1 (CAR 1: $\left.\theta<30^{\circ}\right)$. The second is a bifurcated cusp, consisting of two latitudinally separated forms/branches, when the IMF clock angle lies in the range: $30^{\circ}<\theta<90^{\circ}$ (CAR 2 ). The third cusp aurora is typically located within $70^{\circ}-75^{\circ} \mathrm{MLAT}$, during southward IMF orientation $\left(\right.$ CAR 3: $\left.\theta>90^{\circ}\right)$. A characteristic feature of the last category is the sequence of quasi-periodic auroral breakup events and accompanying poleward moving auroral forms (PMAFs) (Sandholt et al., 1986, 1990, 1993). These auroral forms have been observed to be associated with a stepped cusp ion precipitation signature which has been attributed to a pulsed mode of magnetopause reconnection (Farrugia et al., 1998a; Lockwood and Smith, 1994). The auroral observations indicate that the magnetospheric erosion associated with the individual events is modest. The equatorward boundary of the $630 \mathrm{~nm}$ aurora in the cusp region, a good monitor of the open-closed field line boundary, typically shifts equatorward by less than $50 \mathrm{~km}$ during 
the individual events in the sequence. After a long sequence of events, the net magnetospheric erosion is, however, significant (Sandholt et al., 1998d). At present there is no indication of a solar wind driver of these solar wind-magnetosphere-ionosphere coupling events, such as pressure pulses or IMF discontinuities (Russell et al., 1997). Both theory and observations indicate the importance of the IMF $B_{y}$ component for the activation and subsequent dynamics of the transient reconnection events with their auroral signature (e.g., Lysak et al., 1995; Sandholt et al., 1993).

Theory predicts that southward turnings of the IMF should give rise to magnetospheric erosions and associated equatorward shifts and longitudinal expansions of the cusp (Crooker et al., 1991, Cowley, 1998). The ground-based auroral observations in the cusp region enable quantitative tests of such model predictions. An observation of a cusp auroral expansion far into the prenoon sector (0800 MLT) driven by a strong IMF southward transition during strongly positive IMF $B_{y}$ conditions has recently been reported by Farrugia et al. (1998b) and Sandholt et al. (1998c).

In this study we document the detailed two-dimensional response of the dayside aurora to a sharp southward turning $\left(\sim 90^{\circ}\right)$ of the IMF under negative IMF $B_{y}$ conditions. Observations from two ground sites, separated by two hours in magnetic local time (MLT), covering the $\sim 1200-1600$ MLT region, are reported. This is an ideal location for studies of cusp dynamics under the actual IMF orientation.

By using all-sky camera images and ground magnetograms in conjunction with the MSP data, we are able to reveal further details of the auroral response to southward turnings of the IMF not included in previous work. Thus, for example, we show that the initial threephase expansion is followed by a contraction. In addition, the local magnetic disturbances from a dense chain of stations on Svalbard are described and pulsations in the aurora on one hand and in the magnetic field, on the other, are brought into association. The ground magnetometer data enables us to detail the auroral dynamics in the framework of the ionospheric convection response to pulsed reconnection proposed by Cowley and Lockwood (1992).

\section{Solar wind and IMF observations}

Figure 1 shows solar wind plasma and magnetic field observations obtained from the Wind spacecraft for the interval 0900-1200 UT on 30 November, 1997. The proton data are at $\sim 90 \mathrm{~s}$ and the magnetic field data are at $\sim 3$ s resolution, respectively. At 0900 UT Wind was located at $(196,-3,27) R_{E}$, i.e. it was close to the EarthSun line, which means it is a very useful monitor of IMF conditions affecting the magnetosphere. Shown from top to bottom are the solar wind density, the bulk speed, the proton temperature, the dynamic pressure, the total magnetic field and the GSM field components $B_{x}, B_{y}$, and $B_{z}$, and the IMF clock angle in units shown in Fig. 1. The solar wind parameters were quite steady in this interval, i.e., the average density was $9 \mathrm{~cm}^{-3}$, the bulk speed was $\sim 400-450 \mathrm{~km} \mathrm{~s}^{-1}$, and the dynamic pressure was $2 \mathrm{nPa}$. The total magnetic field was $\sim 8$ $10 \mathrm{nT}$, and $B_{x}$ and $B_{y}$ were positive and negative, respectively. The $B_{z}$ component underwent a large change from strongly positive $(5 \mathrm{nT})$ to strongly negative $(-5 \mathrm{nT})$ between 0955 and $1002 \mathrm{UT}$ and stayed at an average value of $-5 \mathrm{nT}$ during the next $30 \mathrm{~min}$. This was followed by a more gradual northward turning, leading to near zero or positive $B_{z}$ values between 1040 and $1200 \mathrm{UT}$. Associated with the major southward turning, the IMF clock angle changed initially from $40^{\circ}$ to $70^{\circ}$ between 0955 and $1000 \mathrm{UT}$ and then abruptly from $70^{\circ}$ to $130^{\circ}$ at 1002 UT. A simple estimate of the propagation delay from Wind to the Earth's magnetopause, associated with the major southward turning, gives $\sim 56 \mathrm{~min}$. This means that the major auroral response is expected to occur at $\sim 1058$ UT.

\section{Auroral and magnetic observations}

Figure 2 shows meridian scanning photometer (MSP) observations at 630.0 and $557.7 \mathrm{~nm}$ for the interval 1000-1230 UT on 30 November, 1997, obtained from Ny Ålesund, Svalbard (75.5 MLAT). In this interval the Ny Ålesund meridian spans the 1300-1530 magnetic local time (MLT) sector. We note the moderate intensities of both emission lines in the form of two latitudinally separated bands during the interval 1000 1100 UT. The coexistence of two auroral forms have in the past been associated with a clock angle $\theta$ within $\sim 30^{\circ}-90^{\circ}$, i.e., CAR 2. This is consistent with the present observations.

The auroral form in the vicinity of zenith contains some $(\sim 1 \mathrm{kR})$ green line emission, while the aurora further north is strongly red line dominated. A strong auroral brightening occurred in both emission lines at 1100 UT. The initial brightening, which occurred slightly south of zenith, was followed by a poleward expansion and a sequence of similar poleward moving events in the interval 1100-1200 UT. In this interval the auroral equatorward boundary moved equatorward from $10^{\circ}$ south of zenith to $60^{\circ}$ south. The detailed 2dimensional evolution of the aurora will be discussed when we consider all-sky camera images.

Figure 3 shows a color-coded plot of the red line MSP observations, that is, line-of-sight auroral intensities versus zenith angle and time, for the interval 10501150 UT. The intensity scale is given at the bottom of the figure. The initial auroral brightening is seen at $\sim 15^{\circ}$ south of zenith at 1102 UT. The bright form, containing $\sim 10 \mathrm{kR}$ of red line intensity, expanded poleward between 1106 and $1109 \mathrm{UT}$, moving from $15^{\circ} \mathrm{SZ}$ to $25^{\circ} \mathrm{NZ}$. Then the appearance of a higher-latitude form occurred at 1110 UT. This form moved further north during the interval 1110-1116 UT. A second similar auroral event was observed within 1107-1117 UT. The lower-latitude aurora disappeared from the Ny Alesund meridian at 1115 UT, and was absent until 1122 UT, when a new 
WIND/SWE/MFI November 30, 1997 (GSM)

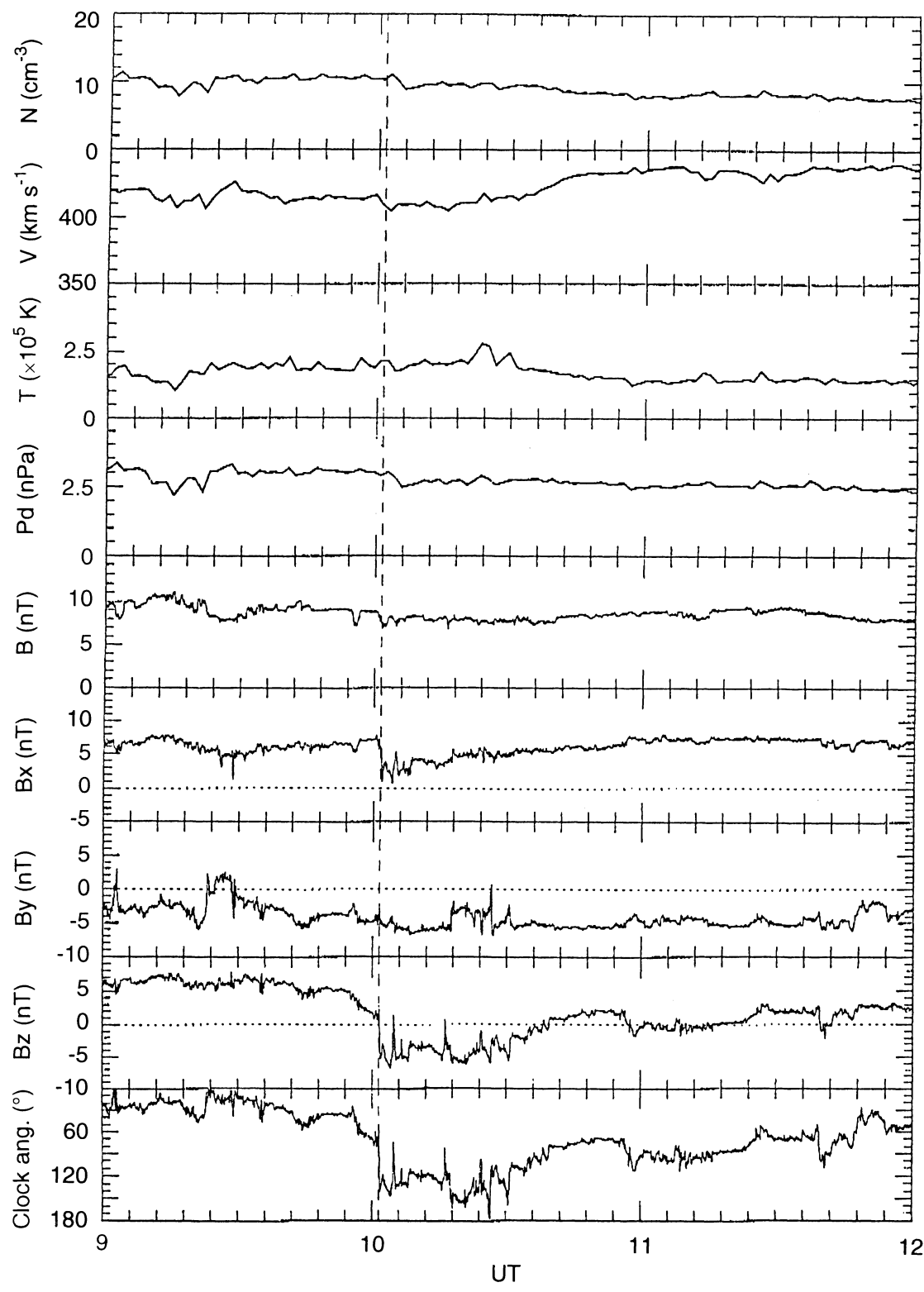

Fig. 1. Solar wind plasma and IMF observations from Wind on November 30, 1997. Shown from top to bottom are proton density (in $\mathrm{cm}^{3}$ ), bulk speed (in $\mathrm{km} / \mathrm{s}$ ), proton temperature (in $\mathrm{K}$ ), dynamic pressure (in $\mathrm{nPa}$ ), the magnetic field magnitude and components $B_{x}, B_{y}$, and $B_{z}$ (in $\mathrm{nT}$ ) and the IMF clock angle (degree). The southward turning of the IMF at 1000 UT is marked by a vertical line form appeared. After 1122 UT a sequence of brightenings, marked by red color at progressively increasing zenith angles to the south, is observed. The equatorward boundary moved equatorward from $25^{\circ}$ south of zenith to $55^{\circ}$ south of zenith at $1150 \mathrm{UT}$. Each major brightening was followed by a poleward moving auroral form (PMAF) at higher latitude. These PMAFs reached far north of zenith before they faded out after $\sim 10 \mathrm{~min}$. Assuming a peak emission altitude of $250 \mathrm{~km}$ for the red line, the PMAFs typically span a latitude range of 400$500 \mathrm{~km}$, that is, the latitudinal distance from the initial brightening to the fading. The poleward expansion speed is thus $\sim 0.5-1 \mathrm{~km} \mathrm{~s}^{-1}$. The average recurrence time between PMAFs is $4 \mathrm{~min}$. Brightenings at the equatorward boundary are even more frequent, since they recur every two min. The major brightenings followed by poleward motion is marked by arrows in Fig. 3.
Figure 4 shows meridian scanning photometer observations from Danmarkshavn, on the east coast of Greenland $\left(77^{\circ} \mathrm{MLAT}\right)$. At this station $1100 \mathrm{UT}$ corresponds to $\sim 1230$ MLT. During the the interval 1000 1045 UT the aurora appears in the form of a persistent band north of zenith and more short-lived forms in the vicinity of zenith. A significant intensification of the aurora in the zenith and a disappearance of the band in the north occurred at $\sim 1051 \mathrm{UT}$. This was followed by a form migrating poleward and fading slowly in the period 1056-1102 UT. Then a major brightening and a significant equatorward shift of the auroral equatorward boundary occurred at $1101 \mathrm{UT}$, before the instrument was turned off at $1102 \mathrm{UT}$. We note the strong intensification of the green line aurora at 11011102 UT. At this time the equatorward boundary moved from $10^{\circ}$ south of zenith to $30^{\circ}$ south at 


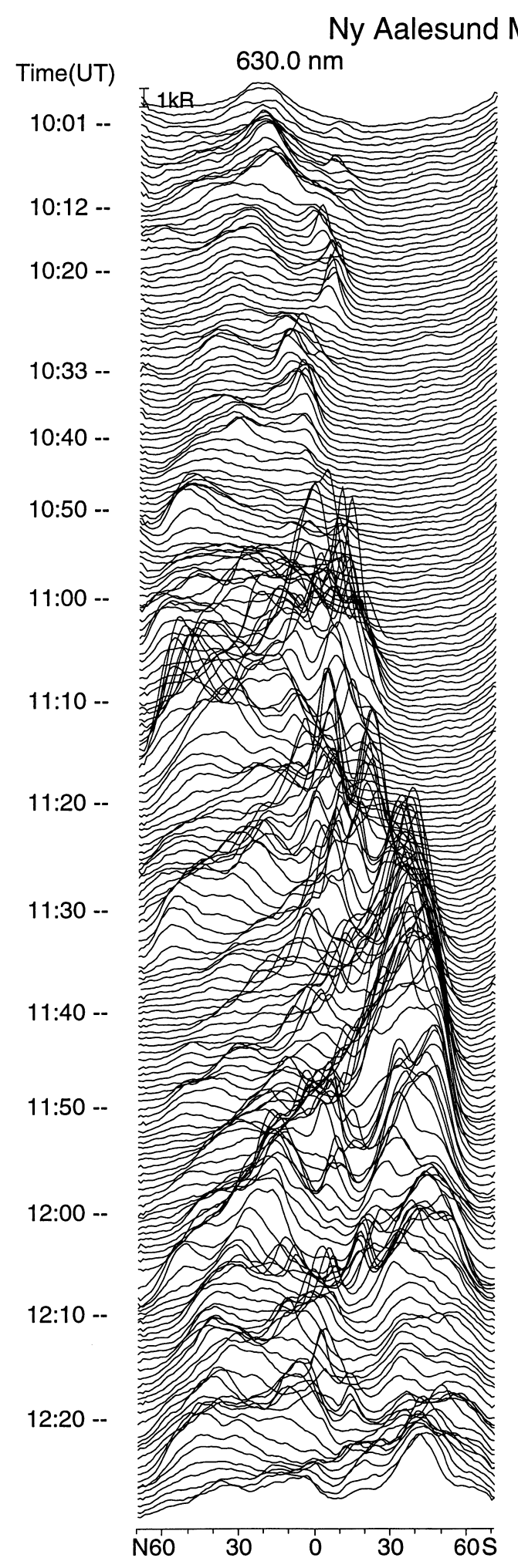

\section{NOV 30, 1997

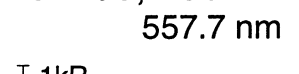

$I 1 \mathrm{kR}$

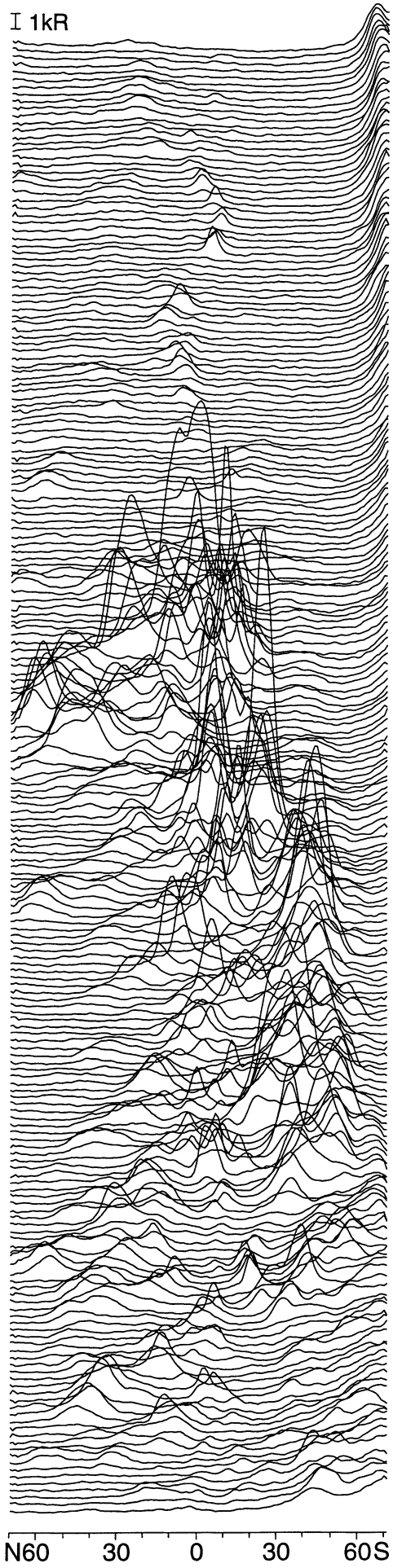

Fig. 2. Meridian scanning photometer (MSP) plots of auroral observations from Ny Ålesund (at 630.0 and $557.7 \mathrm{~nm}$ ) during the interval 10001230 UT on November 30, 1997
$630.0 \mathrm{~nm}$. This corresponds to a latitudinal distance of $\sim 100 \mathrm{~km}$.

Figure $5 \mathrm{a}-\mathrm{c}$ shows sequences of auroral images taken by an all-sky camera in Ny Ålesund on 30 November, 1997. Figure a and b covers the intervals 1039-1154 and 1100-1117 UT, respectively. Images at $630.0 \mathrm{~nm}$ are projected onto an Earth-centered sphere at $250 \mathrm{~km}$ altitude. The grid represents a geographic coordinate system. Latitude circles at $70^{\circ}$ and $80^{\circ}$ as well as meridians separated by $10^{\circ}$ are shown. Svalbard is located in the center of the image and the east coast of Greenland is near the boundary of the field of view on the left side. The field of view of the MSP is marked by an arrowed white line. Figure $5 \mathrm{c}$ is a standard (unpro- 

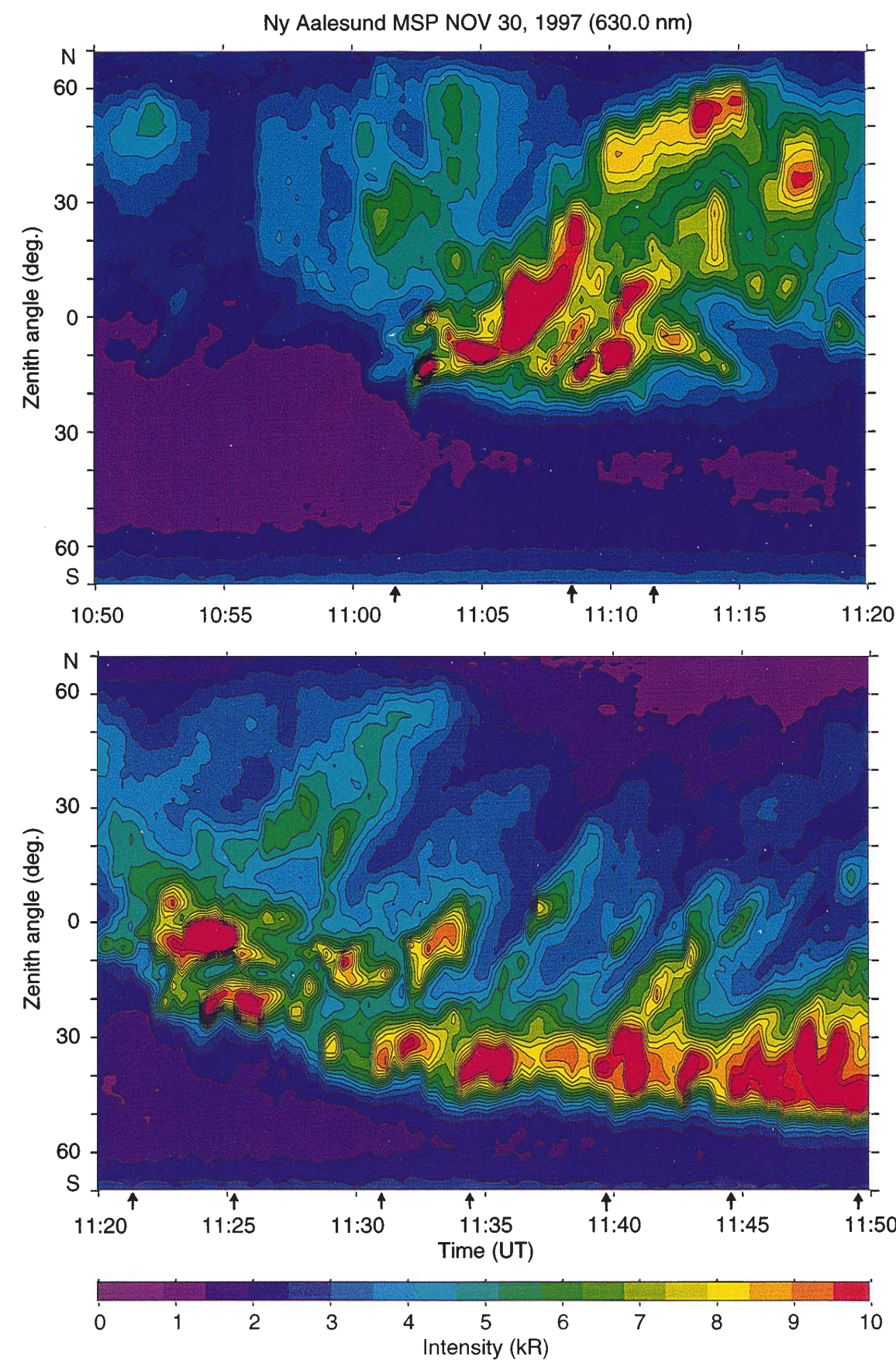

Fig. 3. Color-coded contour plot of $\mathrm{Ny}$ Alesund meridian scanning photometer (MSP) observations at $630 \mathrm{~nm}$ for the interval 1050-1150 UT on November 30, 1997. Arrows along the horizontal axis mark ground magnetic deflections (see Fig. 6) jected) all-sky image sequence for the interval 1100 1117 UT. This format is included for a detailed study of the evolution of the aurora and to avoid possible distortions due to projection.

Figure 5a illustrates the auroral conditions before the major southward turning, while Fig. 5b, c refers to the conditions minutes after the southward turning. Thus, the latter figures provide supplementary 2-dimensional information on the MSP data of Figs. 2-4. Figure 5a shows the evolution of forms north of zenith. The first panel shows two latitudinally separated forms, the northernmost being much weaker, consistent with the Danmarkshavn MSP observations in Fig. 4. The Danmarkshavn MSP intersects these forms. Minor bright- enings are seen at 1042 and during 1051-1054 UT. By 1048 UT the northernmost form had faded while the equatorward form intensified visibly and expanded both west and east.

Figure $5 \mathrm{~b}$ starts 6 min after the last image of Fig. 5a. The first image documents the initial equatorward expansion consequent upon the arrival of the southward turning of the IMF. Furthermore, a new form is appearing to the east of Svalbard. By 1102 UT the first form on the western side of Svalbard had expanded further south and eastward. At this time this form entered the field of view of the MSP in Ny Alesund (see Fig. 3). The eastward expansion continued very visibly up to the 1104 UT image which also shows that the 


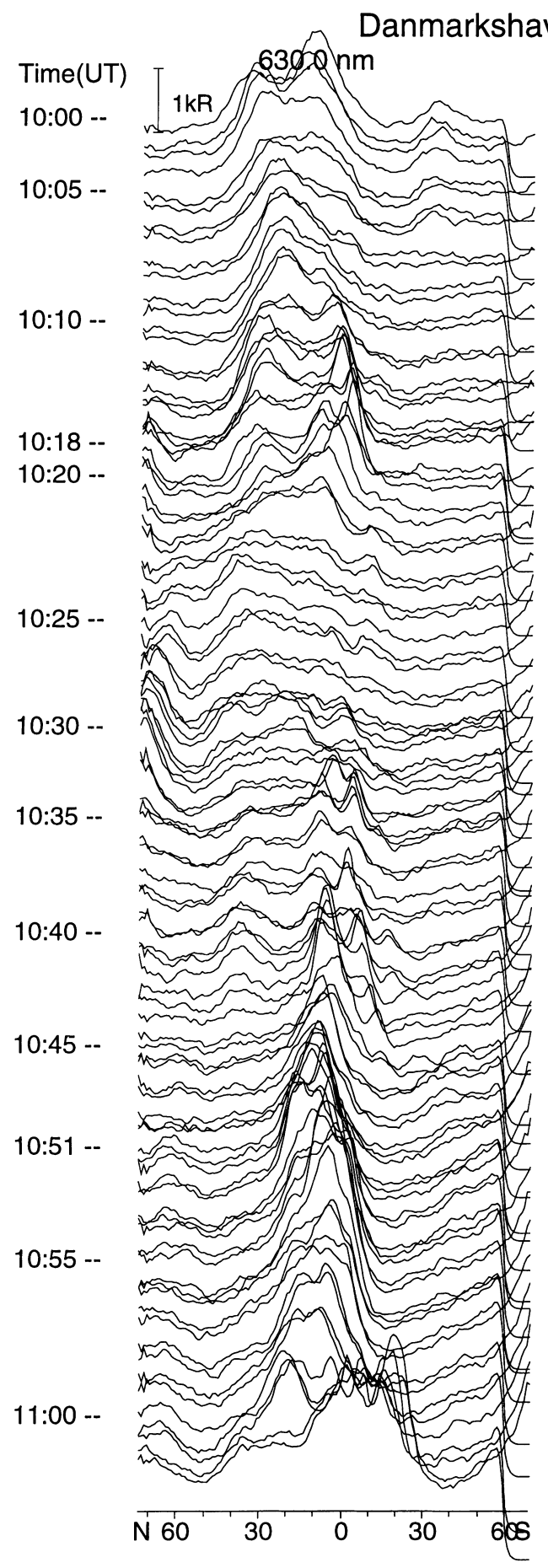

NOV 30, 1997

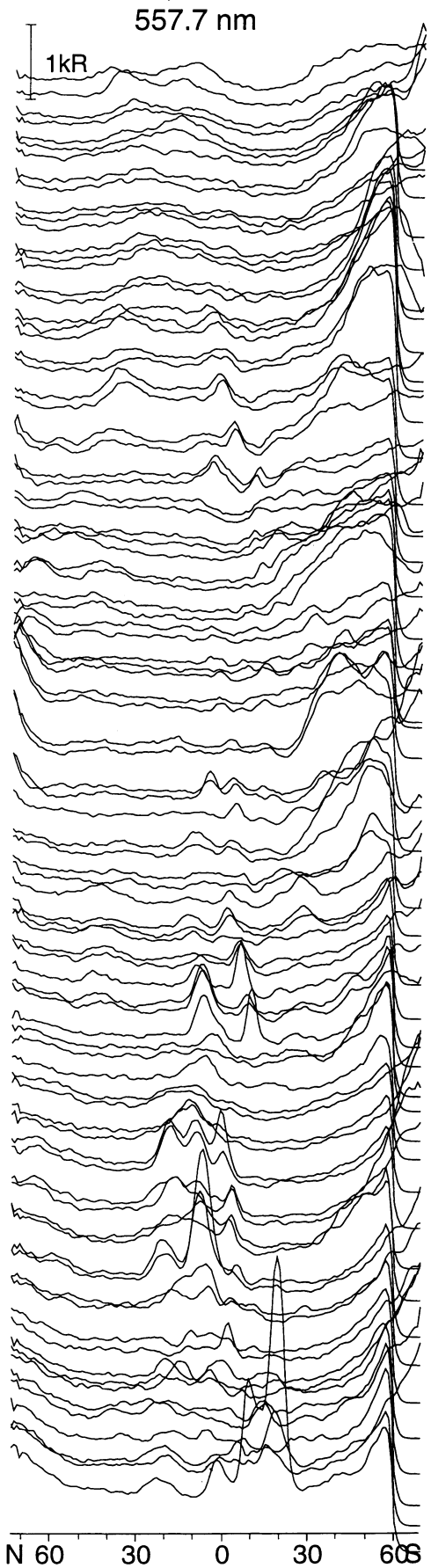

Fig. 4. MSP observations from Danmarkshavn, Greenland of auroral emissions at 630.0 and $557.7 \mathrm{~nm}$ for the interval $1000-1102$ UT on November 30, 1997 eastern form had intensified and fanned out towards the east and north. A further development is documented in the 1106 UT image showing further eastward advances and activation to the north of Svalbard. A contraction of the southernmost form sets in around 1112 UT and has well progressed by the time of the last image (1117 UT), by which time the cusp form had contracted westward and out of the field of view of the Ny Alesund MSP. The brightening at $40^{\circ} \mathrm{N}$ of zenith and seen in the
Fig. 5a-c. False color representation of all-sky auroral images at $630 \mathrm{~nm}$ for the intervals a 1039-1054 UT, b and c 1100, 1102, 1104, 1106, 1112, and 1117 UT on 30 November, 1997. Figure a, b shows auroral images projected to an Earth-centered sphere at $250 \mathrm{~km}$ altitude. The reference frame is geographic coordinates. Latitude circles at $70^{\circ}$ and $80^{\circ}$ as well as meridians separated by $10^{\circ}$ are shown. c shows unprojected images in zenth angle-azimuth angle plots. Geographic north $(\mathrm{N})$ is at the top and east (E) to the right in these images. The photometer scanning meridian is indicated by white arrowed line 

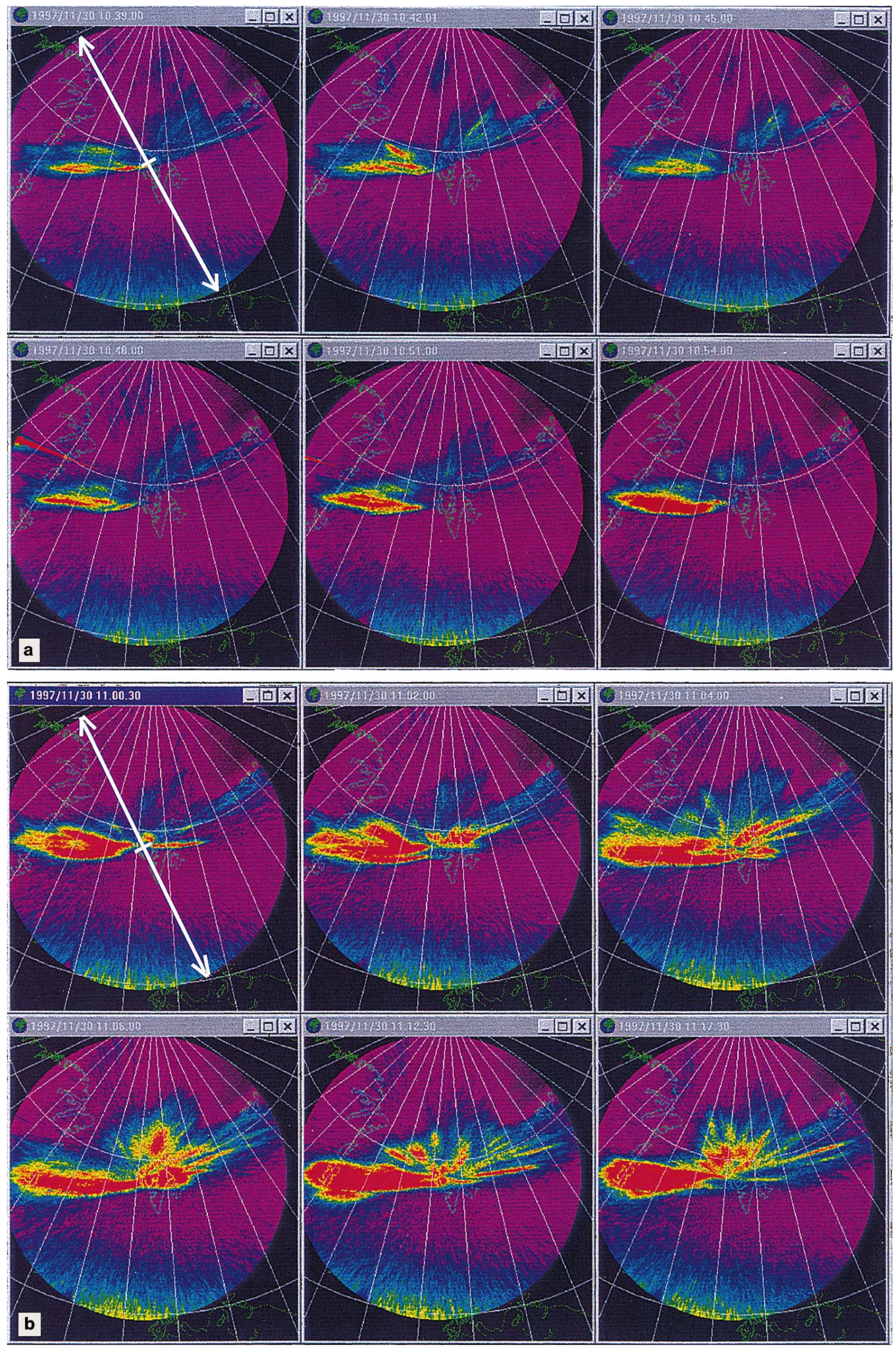


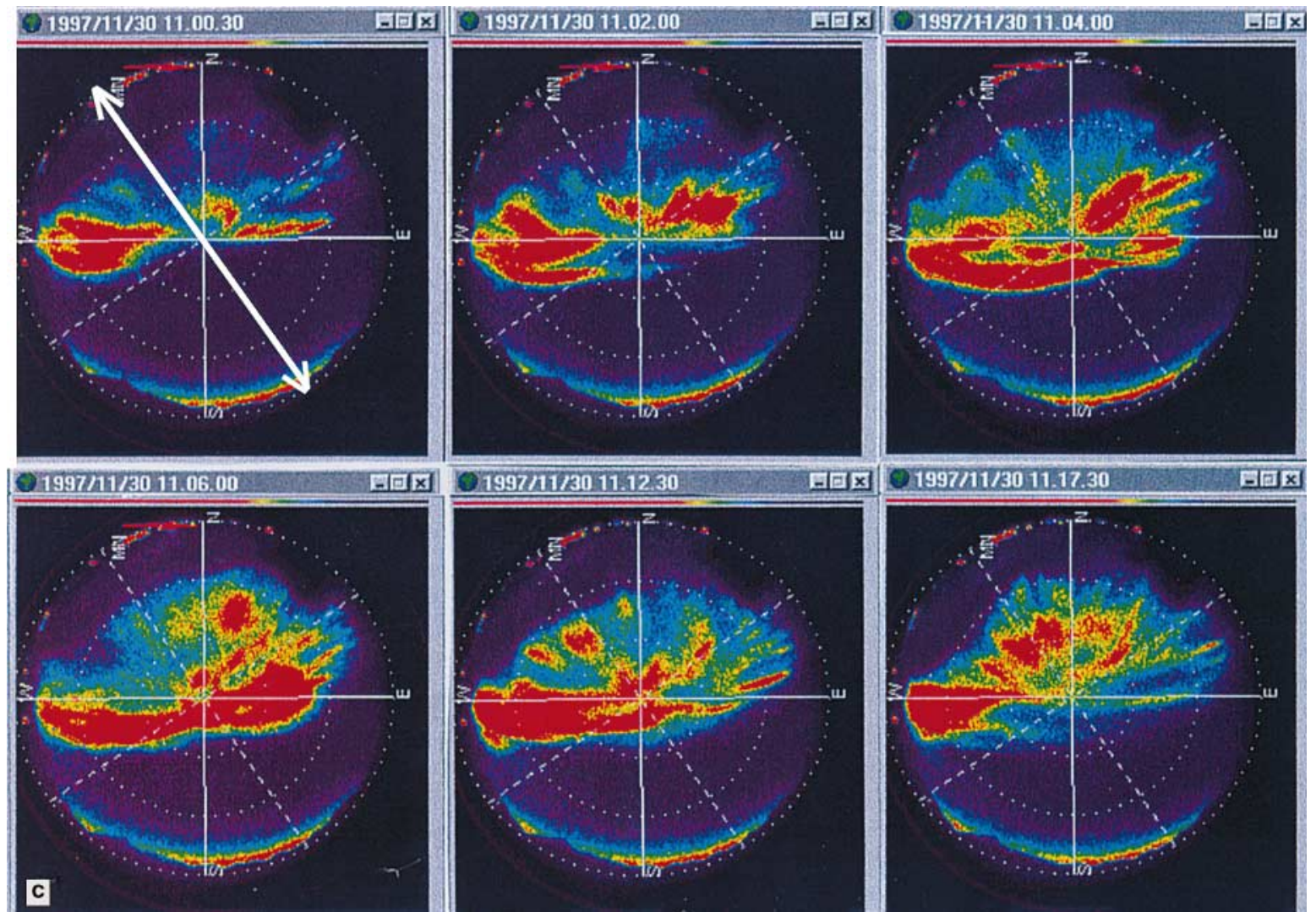

Fig. 5c

MSP after 1110 UT corresponds in the all-sky camera (ASC) images to the longitudinal expansion of the northernmost form in the ASC, thereby entering the MSP (Ny Alesund) field of view at this time.

Details of this auroral evolution are confirmed in the unprojected ASC images in Fig. 5c. Note that the orientation of the Fig. $5 \mathrm{c}$ images is marked by the magnetic meridian (photometer scanning plane). In particular the following features come out clearest in the unprojected images, (1) the eastward expansion between 1102 and 1106 UT, (2) the multiplicity of latitudinally separated forms around 1112 UT which can be easily associated with the MSP observations of partly overlapping (in time) PMAFs in Fig. 3, (3) the westward contraction of the southernmost aurora and the bright aurora in the north corresponding to the late phase of the second event in the last image.

Figure 6 shows $\mathrm{X}$ - and Z-component magnetograms from Ny Ålesund (NAL; $75^{\circ}$ MLAT), Longyearbyen (LYR; $74^{\circ} \mathrm{MLAT}$ ), Hornsund (HOR; $73^{\circ} \mathrm{MLAT}$ ), Hopen (HOP; $72^{\circ} \mathrm{MLAT}$ ) and Bjørnøya (BJN; $71^{\circ}$ MLAT) for the interval $1000-1200$ UT on 30 November, 1997. A rapid increase in the X-component is seen at all stations close to $1100 \mathrm{UT}$, with the maximum deflection $(\sim 40-50 \mathrm{nT})$ occurring at the latitudes of Hornsund-Hopen $\left(72^{\circ}-73^{\circ}\right.$ MLAT). Positive X-deflections correspond to eastward ionospheric Hall current and westward (Sunward) convection. A sequence of shortlived positive X-deflections occurred in the interval
1100-1200 UT. The times at which these deflections occur have been marked by arrows in the MSP plot in Fig. 3. These magnetic perturbations show a one-to-one correspondence with the individual auroral brightenings/expansions. At $\sim 1117$ UT the deflection decreased to values prior to $1100 \mathrm{UT}$. This was the time when the optical data show a westward contraction of the aurora, which also returned to the state prior to 1100 UT. The Z-component deflections are indicative of the latitudinal location of the source current. We note the two major abrupt negative Z-deflections at 1100 and 1119 UT in Ny Alesund (NAL) and Longyearbyen (LYR).

\section{Discussion}

We have documented clear auroral responses to an abrupt turning of the IMF from north to south. IMF $B_{y}$ was negative throughout and the solar wind plasma

Fig. 7. Schematic summary of the location of auroral forms in MLAT/MLT coordinates, representing the times $t_{0}$ (1058 UT), $t_{1}$ (1104 UT), $t_{2}$ (1108 UT) and $t_{3}$ (1115 UT).The circle marks the approximate field of view of the red line filtered all-sky camera in $\mathrm{Ny}$ Alesund. Arrowed meridian lines indicate the field-of-view of meridian scanning photometers (MSPs) in Danmarkshavn (near 1300 MLT) and Ny Alesund (near 1430 MLT), representing $\sim 1100$ UT. The estimated location of the ionospheric projection of the magnetopause reconnection line is shown by dashed curved line 
IMAGE magnetometer network 1997-11-30

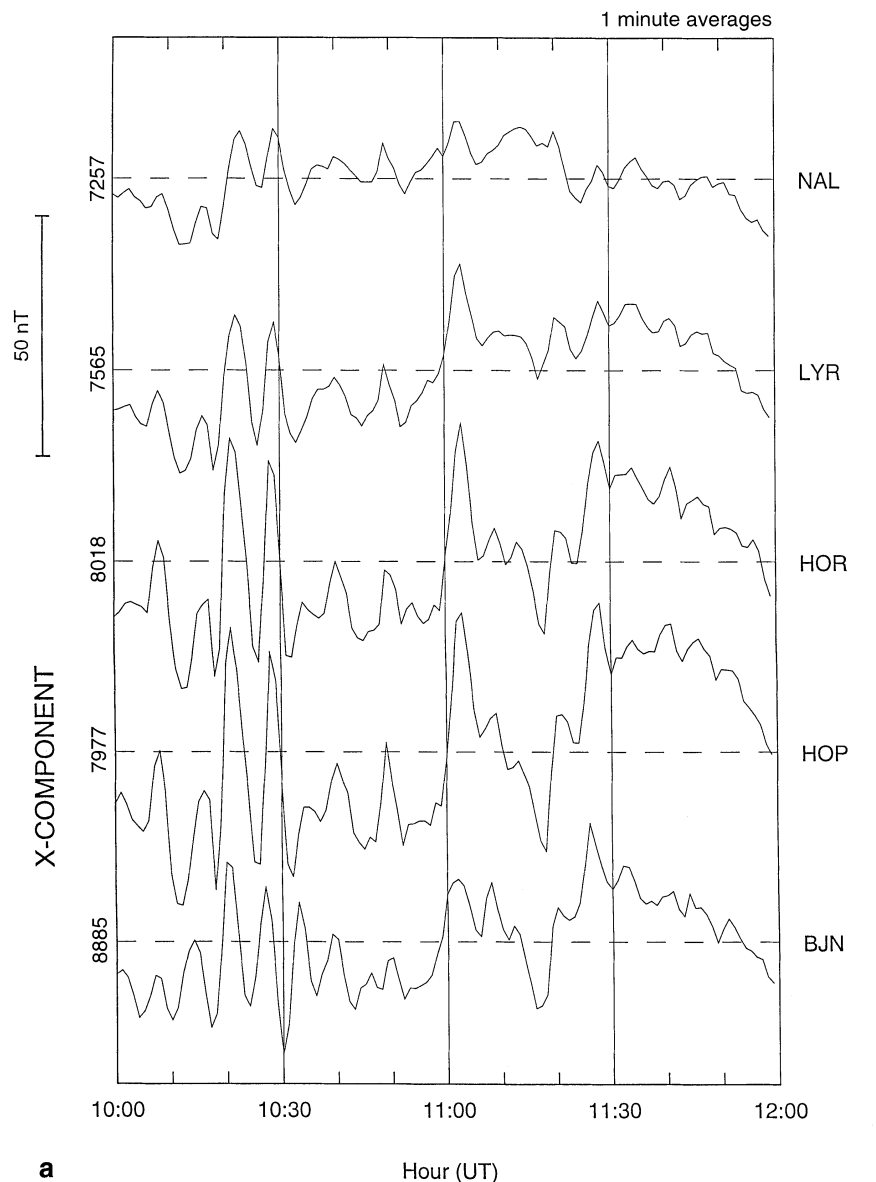

IMAGE magnetometer network 1997-11-30

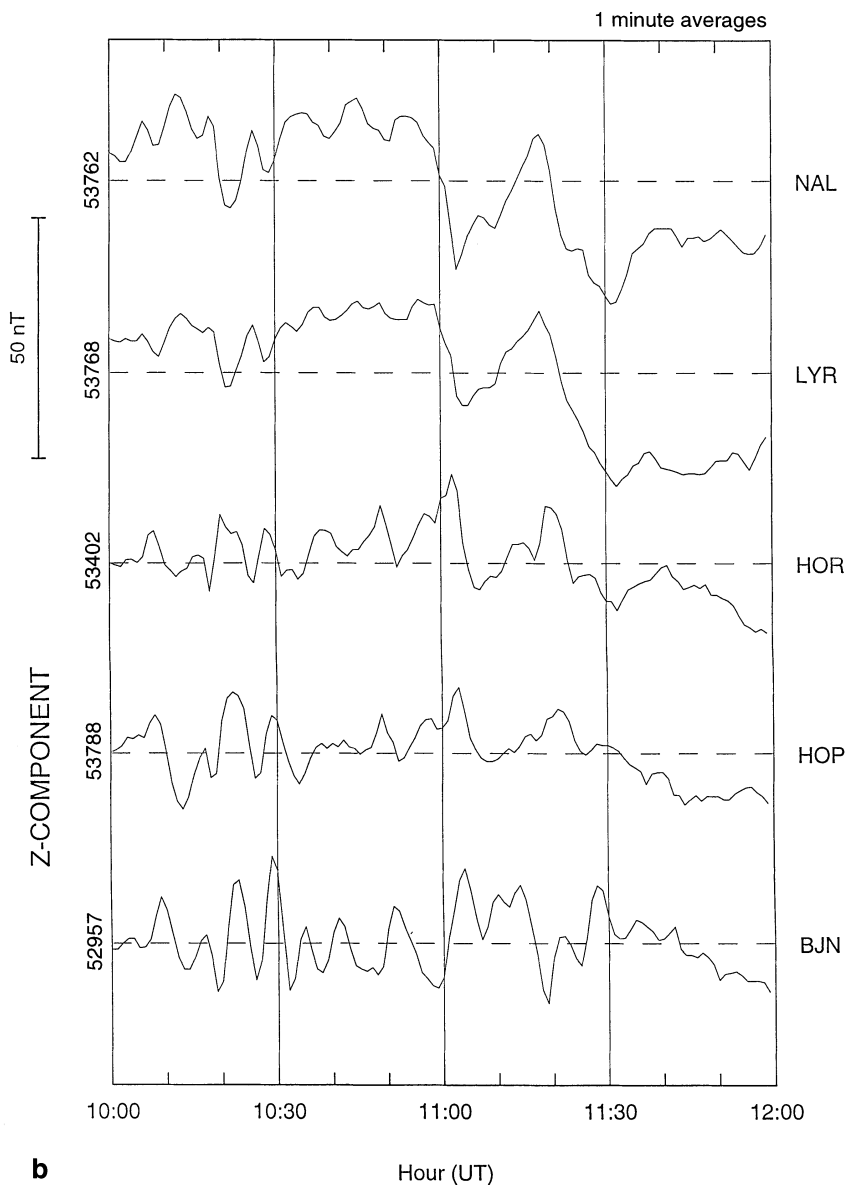

Fig. 6a. X- and b Z-component magnetograms from Ny Ålesund ( $N A L ; 75^{\circ}$ MLAT), Longyearbyen $\left(L Y R ; 74^{\circ} \mathrm{MLAT}\right), \mathrm{Hornsund}(H O R$; $73^{\circ}$ MLAT), Hopen (HOP; $2^{\circ}$ MLAT) and Bjrnya (BJN; $\left.71^{\circ} \mathrm{MLAT}\right)$ for the time interval $1000-1200$ UT on 30 November, 1997

$\begin{array}{llll}70 & 80 & 90 & 80\end{array}$

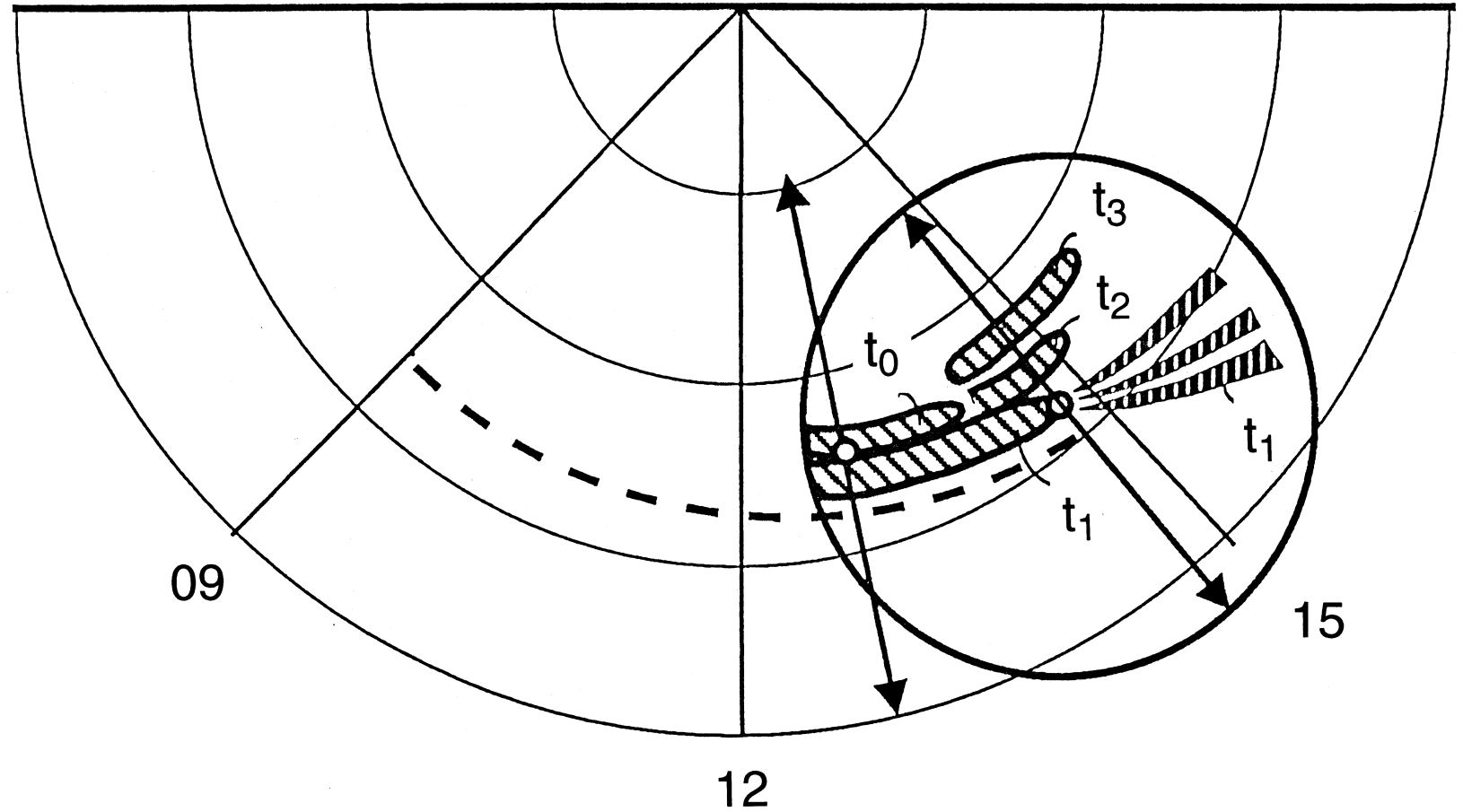


conditions were quite stable. The auroral forms consist of a cusp-type aurora in the $\sim 1200-1500$ MLT sector and fan-arcs located beyond 1500 MLT. A schematic summary of the main features of the auroral observations are given in Fig. 7. The locations of the auroral forms are shown in an MLAT/MLT coordinate system. The time markings $t_{0}, t_{1}, t_{2}$, and $t_{3}$ indicate the auroral evolution during the interval from $1058\left(t_{0}\right)$ to 1115 UT $\left(t_{3}\right) . T_{0}$ represents the auroral condition before the major southward turning, whereas $t_{1}$ and $t_{2}$ mark the approximate locations of the first major auroral event at 1104 and 1108 UT, respectively. The multiple arcs fanning out towards east which were activated at $\sim 1100$ UT are marked at $t_{1}$ (1104 UT). Thus, the initial response (at $\sim 1100$ UT) to the main southward turning of the IMF consisted of a significant intensification, both in the red line at $630.0 \mathrm{~nm}$ and the green line at $557.7 \mathrm{~nm}$, and a $\sim 100 \mathrm{~km}$ equatorward shift of the equatorward boundary of the cusp aurora at around 1200-1300 MLT/ $75^{\circ}$ MLAT. This was followed by an eastward expansion into the field of view of the Ny Alesund photometer (MSP; see Fig. 7), bringing the cusp eastern boundary close to the 1500 MLT meridian within the next $5 \mathrm{~min}$. In the interval 1108-1115 UT a second event overlaps in time with the later phase of the first event, also seen in the magnetograms of Fig. 6. This phase included a longitudinal expansion of the auroral form at high latitude $\left(\sim 78^{\circ} \mathrm{MLAT}\right)$ at the time when the second auroral expansion was observed further south. A westward contraction of the lower latitude cusp aurora occurred after 1112 UT. A new activation/expansion occurred at $\sim 1120$ UT. The latter initiated a sequence of auroral brightenings at the equatorward boundary of the preexisting luminosity and poleward moving auroral forms (PMAFs) with a duration of typically $10 \mathrm{~min}$ each. In this phase the auroral equatorward boundary at the Svalbard meridian migrated equatorward from $74^{\circ}$ to $73^{\circ}$ during a $12 \mathrm{~min}$ period (1123-1135 UT).

These observations are interpreted as follows. The initial auroral events which occurred during the $15 \mathrm{~min}$ period between 1100 and 1115 UT may be considered to be the response to initial pulses of dayside magnetopause reconnection in the presence of negative IMF $B_{y}$, as described by Cowley (1998). The idea of Cowley and Lockwood (1992), illustrated schematically in Fig. 8, is that a pulse of reconnection creates a patch of new open flux which is appended to the boundary near noon, as shown in Fig. 8a. According to Cowley (1998) the openclosed field line boundary will initially jump equatorward, and precipitating accelerated magnetosheath plasma will produce a new patch of cusp emission. The magnetic tension force for IMF $B_{y}<0$ will initially give rise to eastward flow within the patch (Fig. 8b), and the flow will close in the ionosphere mainly in a single vortex on closed field lines. "These flows will dominate in the ionosphere for intervals of $\sim 5 \mathrm{~min}$, leading to displacements of the patch of open flux around the boundary of $\sim 1000 \mathrm{~km}(\sim 2 \mathrm{~h}$ of MLT) at speeds of $2-$ $3 \mathrm{~km} \mathrm{~s}^{-1}$. Eventually, however, the open tubes will have contracted over the dayside boundary and will then be pulled by the magnetosheath flow into the tail. The open flux will then move predominantly poleward with the excitation of twin-vortex flow (Fig. 8c), while the cusp auroras will start to fade as the magnetosheath source to the ionosphere is shut off" (Cowley, 1998). This theoretical description is generally in very good agreement with the auroral observations during the interval 1100 1115 UT on 30 November, 1997, which may also be separated into three phases.

Phase $1(1100-1102$ UT) is the initial brightening and $100 \mathrm{~km}$ equatorward shift of the aurora/open-closed field line boundary near 1200-1300 MLT. Phase 2 (1102-1106 UT) consists of an eastward expansion of the cusp aurora, reaching the 1430 MLT meridian by 1106 UT. An expansion speed of $\sim 1-2 \mathrm{~km} \mathrm{~s}^{-1}$ is estimated, which compares rather well with Cowley's (1998)
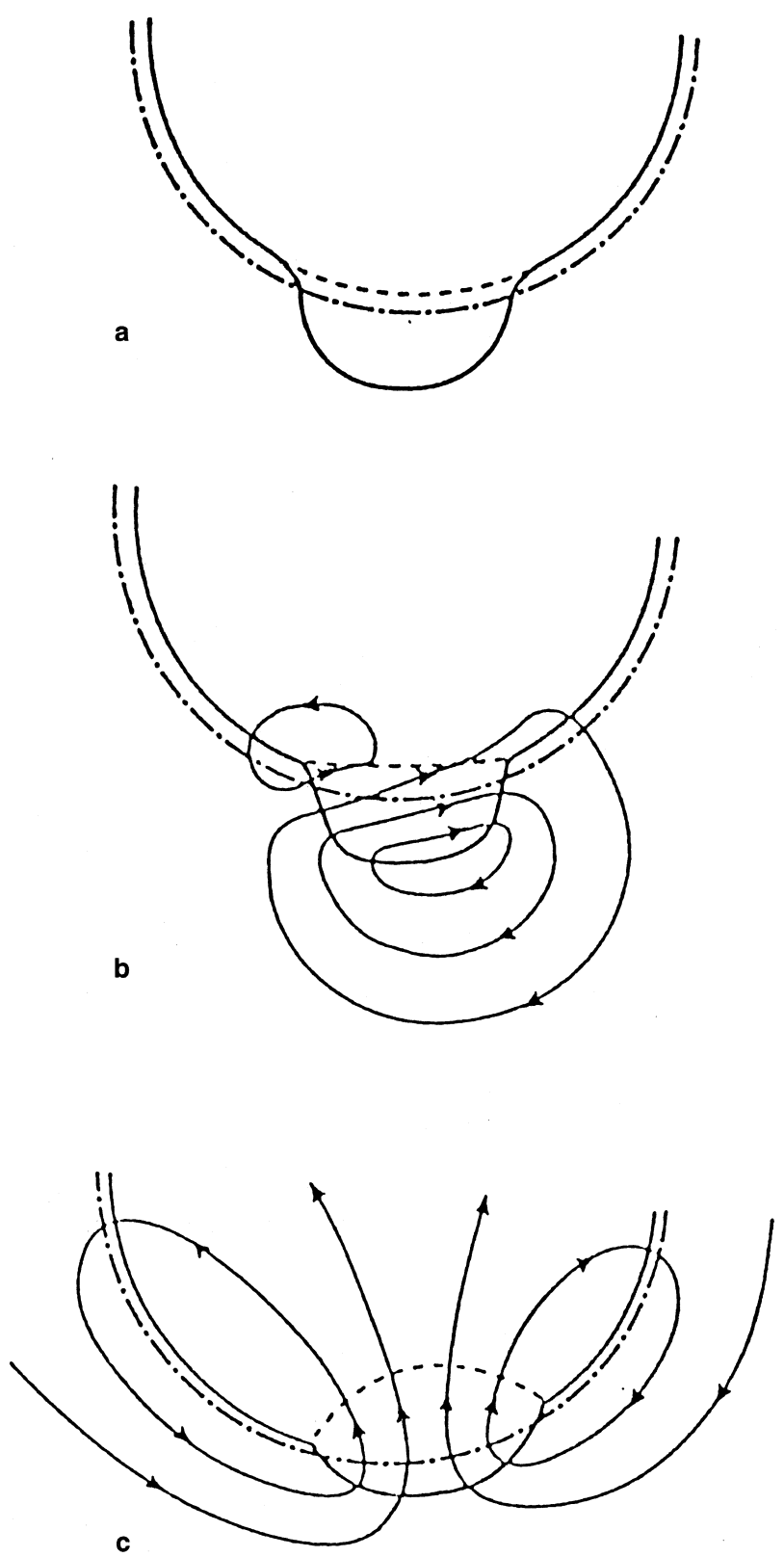

Fig. 8a-c. Three phase model of the ionospheric response to a single pulse of magnetopause reconnection (from Cowley, 1998) 
prediction. Phase 3 (1106-1115 UT), is characterized by poleward auroral motion and east-west expansion of the auroral form at $\sim 77^{\circ}-78^{\circ}$ MLAT. In this interval a second auroral event appeared at $\sim 75^{\circ}$ MLAT.

The cusp expansions at 1100 and 1120 UT are both clearly manifested in the local magnetograms in Fig. 6. The positive $\mathrm{X}$-component deflections maximizing at the latitudes of Hopen $\left(72^{\circ} \mathrm{MLAT}\right)$-Hornsund $\left(73^{\circ} \mathrm{MLAT}\right)$ in combination with the negative $\mathrm{Z}$ deflections at the northernmost stations are consistent with corresponding shortlived activations of westward return flow/eastward Hall current $(\delta \mathrm{X}>0)$ on closed field lines equatorward of the cusp, as depicted in Fig. 8b. Xcomponent deflections corresponding to the auroral event sequence in the interval 1120-1150 UT are seen in the magnetometer traces at Longyearbyen, Hornsund and Hopen.

Here we have documented dayside auroral responses to initial pulses of enhanced magnetopause reconnection rate driven by an abrupt southward turning of the IMF. The auroral features which the combination of two meridian scanning photometers and an all-sky imager made us able to illuminate are the following: (1) a threephase evolution of the individual events in the cusp aurora, consisting of an initial $\sim 100 \mathrm{~km}$ equatorward shift, followed by longitudinal and poleward expansions, (2) the local magnetic disturbances and the auroral phenomenon are brought into detailed comparison, demonstrating coherent pulsations in the aurora and the return flow equatorward of the cusp, (3) a phase of auroral contraction which is accompanied by a switch-off of the magnetic disturbance, possibly due to a brief switch-off of the magnetopause reconnection rate, and (4) an additional auroral form (fan-arcs) located duskward of the cusp (in the 1500-1600 MLT sector) is observed to be activated during the phase of initial cusp expansion.

Acknowledgements. We thank Keith Ogilvie and Ronald Lepping, the PI's on the SWE and MFI Investigations on Wind, for the interplanetary data used in the analysis. The IMAGE magnetometer data used were collected as a German-Finnish-Polish-Norwegian project conducted by the Technical University of Braunschweig and the Finnish Meteorological Institute. The auroral observation program on Svalbard is supported by the Norwegian Research Council and the Norwegian Polar Research Institute. The MSP in Danmarkshavn was operated by the Danish Meteorological Institute (DMI), Copenhagen. This work is supported in part by NASA grant NAG5-2834.

Topical Editor K.-H. Glassmeier thanks S.W.H. Cowley and J.P. Villain for their help in evaluating this paper.

\section{References}

Cowley, S. W. H., Excitation of flow in the earth's magnetosphereionosphere system: observations by incoherent-scatter radar, in Polar Cap Boundary Phenomena, Ed J. Moen, A. Egeland, and M. Lockwood, vol. 509 of $C$, pp. 127-140, Kluwer Dordrecht, Netherlands, 1998.

Cowley, S. W. H., and M. Lockwood, Excitation and decay of solar wind-driven flows in the magnetosphere-ionosphere system, Ann. Geophysicae, 10, 103, 1992.

Crooker, N. U., F. R. Toffoletto, and M. S. Gussenhoven, Opening the cusp, J. Geophys. Res., 96, 3497, 1991.

Farrugia, C. J., P. E. Sandholt, W. F. Denig, and R. B. Torbert, Observation of a correspondence between poleward-moving auroral forms and stepped cusp ion precipitation, J. Geophys. Res., 103, 9309, 1998a.

Farrugia, C. J., P. E. Sandholt, J. Moen, and R. L. Arnoldy, Unusual features of the January 1997 magnetic cloud and their effect on optical dayside auroral signatures, Geophys. Res. Lett., in press, $1998 \mathrm{~b}$.

Lockwood, M., and M. F. Smith, Low and middle altitude particle signatures for general magnetopause reconnection rate variations, 1, Theory, J. Geophys. Res., 99, 8531, 1994.

Lysak, R. L., Y. Song, and J. C. Grieger, Coupling of the magnetopause to the ionosphere by means of Alfven waves and field-aligned currents, in Physics of the Magnetopause, Geophys. Monogr. Ser., 90, Ed P. Song, B. U. O. Sonnerup, and M. F. Thomsen, p. 385, AGU, Washington, D. C., 1995.

Russell, C. T., G. Le, H. Kawano, S. M. Petrinec, and T. L. Zhang, Intrinsic time scale for reconnection on the dayside magnetopause, Adv. Space Res., 19(12), 1913, 1997.

Sandholt, P. E., C. S. Deehr, A. Egeland, B. Lybekk, R. Viereck, and G. J. Romick, Signatures in the dayside aurora of plasma transfer from the magnetosheath, J. Geophys. Res., 91, 10 063, 1986.

Sandholt, P. E., M. Lockwood, T. Oguti, S. W. H. Cowley, K. S. C. Freeman, B. Lybekk, A. Egeland, and D. M. Willis, Midday auroral breakup events and related energy and momentum transfer from the magnetosheath, J. Geophys. Res., 95, 1039, 1990.

Sandholt, P. E., J. Moen, A. Rudland, D. Opsvik, W. F. Denig, and T. Hansen, Auroral event sequences at the dayside polar cap boundary for positive and negative interplanetary magnetic field $B_{y}$, J. Geophys. Res., 98, 7737, 1993.

Sandholt, P. E., C. J. Farrugia, and S. W. H. Cowley, Pulsating cusp aurora for northward IMF, J. Geophys. Res., 103, 26507, 1998a.

Sandholt, P. E., C. J. Farrugia, J. Moen, and S. W. H. Cowley, Dayside auroral configurations: responses to southward and northward rotations of the interplanetary magnetic field, J. Geophys. Res., 103, 20279, 1998b.

Sandholt, P. E., C. J. Farrugia, J. Moen, Ø . Noraberg, B. Lybekk, T. Sten, and T. Hansen, A classification of dayside auroral forms and activities as a function of IMF orientation, J. Geophys. Res., 103, 23325, 1998c.

Sandholt, P. E., C. J. Farrugia, M. Øieroset, P. Stauning, and W. F. Denig, Auroral activity associated with unsteady magnetospheric erosion: observations on December 18, 1990, J. Geophys. Res., 103, 2309, 1998d. 